\title{
Effects of Torsion, Detorsion and Melatonin on Testicular Malondialdehyde Level
}

\author{
Effets de torsion, et Detorsion Mélatonine sur Malondialdehyde niveau du testicule
}

\author{
F. I. O. Duru*†, C. C. Noronha* , A. I. Akinwande', A. O. Okanlawon ${ }^{* \S}$
}

\begin{abstract}
BACKGROUND: Unilateral testicular torsion is a cause of bilateral testicular damage, which has ischaemic and reperfusion components. The damage may involve lipid peroxidation leading to production of lipid peroxides in the testes, including malondialdehyde (MDA).

OBJECTIVE: To investigate the MDA variations in the ipsilateral and contralateral testes following ischaemia-reperfusion and the effect of melatonin.

METHODS: Mature adult male Sprague-Dawley rats were divided into 13 groups of 10 each. One control group underwent sham operation. Three groups were subjected to right sided testicular torsion by twisting the testes $720^{\circ}$ counterclockwise for one, three and five hours; three groups were subjected to de-torsion following torsion lasting one, three and five hours; three groups were treated with intra-peritoneal melatonin $(1 \mathrm{mg} / \mathrm{kg})$ before torsion lasting one, three and five hours, and three groups were treated with intra-peritoneal melatonin before de-torsion following torsion lasting one, three and five hours. At the end of the experiment all animals were sacrificed by decapitation and testes were collected for MDA level estimation.

RESULTS: The MDA level was significantly higher in ipsilateral torted testis than the control testis in all groups $(P<0.05)$, with the levels increasing with the duration of torsion. Detorsion significantly increased the MDA level only if the initial torsion was for less than three hours. Melatonin did not significantly affect the MDA level in the ipsilateral testis if administered before torsion, but significantly reduced the level if administered before detorsion.
\end{abstract}

CONCLUSION: Malondialdehyde levels are altered in the both testes following unilateral testicular torsion-detorsion injuries. The reperfusion component of the injury is significant and may be reduced by melatonin. WAJM 2007; 26(4): 312-315.

Keywords: Testes, Ischaemia, reperfusion, Melatonin, Malondialdehyde

\section{RESUME}

CONTEXTE: torsion testiculaire unilatérale est une cause de dommages testiculaire bilatérale, qui a reperfusion ischémiques et composants. Les dommages peuvent impliquer peroxydation lipidique conduisant à la production de peroxydes lipidiques dans les testicules, notamment malondialdehyde (MDA).

OBJECTIF: Etudier les variations de la MDA et controlatérale ipsilateral testicules suivants ischémie-reperfusion et de l'effet de la mélatonine.

MÉTHODES: Mature adulte mâle Sprague-Dawley ont été répartis en 13 groupes de 10 chacun. Un groupe de contrôle ont subi un simulacre opération. Trois groupes ont été soumis à la torsion du testicule droit unilatéral par torsion testiculaire 720 o antihoraire pour un, trois et cinq heures, trois groupes ont été soumis à la suite de la torsion detorsion d'une durée d'un, trois et cinq heures, trois groupes ont été traités avec la mélatonine intra-péritonéale (lmg/kg) avant de torsion d'une durée d'un, trois et cinq heures, et les trois groupes ont été traités avec la mélatonine intra-péritonéale avant de torsion suivants torsion d'une durée d'un, trois et cinq heures. À la fin de l'expérience, tous les animaux ont été sacrifiés par décapitation et les testicules ont été recueillies pour la MDA niveau estimation.

RÉSULTATS: La MDA niveau était nettement plus élevée dans les testicules ipsilateral torted que le testicule contrôle dans tous les groupes $(P<0,05)$, avec des niveaux de plus en plus avec la durée de la torsion. Detorsion considérablement augmenté la MDA que si le niveau initial de torsion a été pendant moins de trois heures. Mélatonine n'a pas d'influence significative sur le niveau de la MDA dans le testicule ipsilateral s'ils sont administrés avant la torsion, mais a sensiblement réduit le niveau s'ils sont administrés avant detorsion.

CONCLUSION: Malondialdehyde niveaux sont modifiées dans la suite de deux testicules torsion testiculaire unilatérale detorsion blessures. La reperfusion composante de la blessure est importante et peut être réduite de mélatonine. WAJM 2007; 26(4): 312-315.

Mots-clés: testicule, Ischaemia, reperfusion, Mélatonine, Malondialdehyde.

Departments of *Anatomy and 'Biochemistry, College of Medicine, University of Lagos.

Correspondence: F. I. O Duru, Department of Anatomy, College Of Medicine, University of Lagos

Abbreviation: MDA, Malondialdehyde. 


\section{INTRODUCTION}

Torsion of the testis is an important acutely painful surgical emergency with significant long-term implications if not promptly identified and treated. ${ }^{1}$ The condition represents one of the most common ischaemia-reperfusion situations encountered in clinical practice. Unilateral testicular torsion is known to eventually cause damage to the contra-lateral testis and may lead to infertility. ${ }^{2}$

An interesting finding in testicular ischaemia-reperfusion is the fact that deleterious changes in the torted testis is eventually mirrored by events in the contra-lateral non-torted testis. This has been demonstrated histo-pathologically and with physical and biochemical markers. ${ }^{3}$ Tissue malondialdehyde levels correlate positively with damage and is widely used as a marker for lipid peroxidation. ${ }^{4}$ Despite the considerable volume of data available on ischaemiareperfusion injury of the testes, there is a dearth of information regarding some aspects of this condition. For example, there is little data to show how the testicular levels of MDA in the torted testis compare with the contra-lateral nontorted testis and how MDA evolve if testis is re-perfused after a sub-lethal duration of ischaemia. Secondly it is not known whether the reperfusion injury has a role in the injury of the contra-lateral testis, and thirdly the effectiveness of an antioxidant and broad spectrum free-radical scavenger like melatonin in minimizing or preventing ipsi-lateral and contra-lateral damage following testicular torsiondetorsion especially if administered before detorsion.

We therefore used an experimental ischaemia-reperfusion rat testis model to study the malondialdyhide variations in the ipsilateral and contralateral testis and to evaluate the effectiveness of melatonin in reducing both ischaemic and reperfusion injuries.

\section{MATERIALS AND METHODS}

Adult male Sprague-Dawley rats weighing 180-200g were divided into 13 groups, each made up of 10 rats. One group underwent sham operation and served as the control. Three groups were subjected to right sided testicular torsion by twisting the testes 720 degrees counterclockwise for 1, 3 and 5 hours; 3 groups were subjected to de-torsion following torsion lasting 1, 3 and 5 hours; 3 groups were treated with intra-peritoneal melatonin $(1 \mathrm{mg} / \mathrm{kg})$ before torsion lasting 1,3 and 5 hours, and 3 groups were treated with intra-peritoneal melatonin $(1 \mathrm{mg} / \mathrm{kg})$ before de-torsion following torsion lasting 1, 3 and 5 hours. At the end of the experiment all animals were sacrificed by decapitation and ipsi-lateral and contralateral testes were collected for malondialdehyde level determination and testicular histology.

\section{Determination of Testicular Malondialdehyde}

Testicular malondialdehyde (MDA) levels were determined using the modified thiobarbituric acid method of Buege and Aust (1978). ${ }^{5}$ MDA reacts with thiobarbituric acid to give a red compound absorbing at $535 \mathrm{~nm}$. The stock reagent contains $2 \mathrm{ml} \quad 15 \% \mathrm{w} / \mathrm{v}$ trichloroacetic acid, $0: 375 \% \mathrm{w} / \mathrm{v}$ thiobarbituric acid and $0.25 \mathrm{~mol} / \mathrm{L}$ hydrochloric acid. A $0.5 \mathrm{~g}$ testicular tissue sample was homogenized in $5 \mathrm{ml}$ of $0.15 \mathrm{MKCl}$ and the homogenate centrifuged at $1000 \mathrm{~g}$ for 10 minutes in a Uniscope laboratory centrifuge and the supernatant collected. An aliquot of $2 \mathrm{ml}$ of the stock reagent was added to $1 \mathrm{ml}$ of testicular homogenate supernatant and mixed thoroughly and placed in an Equitron water bath $\left(80-90^{\circ} \mathrm{C}\right)$ for 15 minutes. It was then cooled and the flocculent precipitate removed by centrifugation at $1000 \mathrm{~g}$ for 10 minutes and the absorbance of the supernatant determined with a Spectronic spectrophotometer at $535 \mathrm{~nm}$ against blank containing all the reagents. Concentration of malondialdehyde was calculated using the molar absorptivity coefficient of malondiadehyde which is $1.56 \times 10^{5} \mathrm{M}^{-1} \mathrm{~cm}^{-1}$.

\section{Statistical analysis}

Data are expressed as mean \pm SD. Differences between groups were assessed using t-test with $\mathrm{p}<0.05$ considered significant.

\section{RESULTS}

MDA levels with ipsilateral torsion alone. There was no significant difference between the MDA levels in the ipsilateral and contralateral testes of the control rats. The MDA level was higher in ipsilateral torted testis than the control testis in all groups with the levels increasing with the duration of torsion. Also, the MDA levels in the ipsilateral torted testis were significantly higher than the levels in the contra-lateral non-torted testis in all groups. MDA levels began to increase significantly in the contralateral testis following more than three hours of torsion (Table 1).

Table 1: Malondialdehyde levels in ipsi-lateral torted and contra-lateral non-torted testis

\begin{tabular}{|c|c|c|}
\hline \multirow[t]{2}{*}{ Group* } & MDA, Mean (SD) & $\mu \mathrm{mol} / \mathrm{mg}$ \\
\hline & Right testis & Left testis \\
\hline A & $0.38 \pm 0.01$ & $0.37 \pm 0.13$ \\
\hline $\mathrm{B}$ & $0.46 \pm 0.04$ & $0.40 \pm 0.21$ \\
\hline $\mathrm{C}$ & $1.28 \pm 0.32^{\dagger}$ & $0.44 \pm 0.16$ \\
\hline $\mathrm{D}$ & $3.10 \pm 0.64^{\dagger}$ & $0.49 \pm 0.30$ \\
\hline
\end{tabular}

*A, B, C, and D = Control right testicular torsion for one, three, and five hours respectively. ${ }^{\dagger} \mathrm{p}<0.05$.

Table 2: Malondialdehyde in ipsi-lateral and contra-lateral testis following torsion-de-torsion).

\begin{tabular}{|c|c|c|}
\hline \multirow[t]{2}{*}{ Group* } & MDA, Mean (SD) & $\mu \mathrm{mol} / \mathrm{mg}$ \\
\hline & Right testis & Left testis \\
\hline A & $0.38 \pm 0.01$ & $\overline{0.36 \pm 0.13}$ \\
\hline $\mathrm{E}$ & $0.89 \pm 0.22^{\dagger}$ & $0.40 \pm 0.14$ \\
\hline F & $2.06 \pm 0.12^{\dagger}$ & $0.42 \pm 0.02$ \\
\hline G & $3.26 \pm 1.01^{\dagger}$ & $0.47 \pm 0.28$ \\
\hline
\end{tabular}

${ }^{*} \mathrm{~A}, \mathrm{E}, \mathrm{F}$, and $\mathrm{G}=$ Control,; detorsion, following testicular torsion for one, three, and five hours respectively, followed by detorsion for 90 minutes $t_{p}<0.05$

MDA levels following torsion-detorsion. There was significantly higher MDA levels in the testes torted for one and three hours (groups $\mathrm{E}$ and $\mathrm{F}$ ) but not in that torted for five hours (group G) (Table 2) compared to their corresponding groups in Table 1. There was no significant difference between the MDA level in the contra-lateral testis in all groups (Table 2) and their corresponding groups in Table 1.

MDA levels with melatonin administered before torsion. There was no significant difference between MDA 
levels in the torted testis of groups $\mathrm{H}, \mathrm{I}$ and $J$ (Table 3), compared to their corresponding testis in groups $\mathrm{B}, \mathrm{C}$ and $D$ (Table 1). There was a significant decrease in the MDA levels in the contralateral testis in all groups (Table 3 ) compared to their corresponding groups in Table 1 .

Table 3: Malondialdehyde in ipsi-lateral and contra-lateral testis with melatonin administered before torsion

\begin{tabular}{|c|c|c|}
\hline \multirow[t]{2}{*}{ Group* } & MDA, Mean (SD) & \multirow{2}{*}{$\begin{array}{l}\mu \mathrm{mol} / \mathrm{mg} \\
\text { Left testis }\end{array}$} \\
\hline & Right testis & \\
\hline $\mathrm{A}$ & $0.38 \pm 0.01$ & $0.36 \pm 0.13$ \\
\hline $\mathrm{H}$ & $0.48 \pm 0.14$ & $0.36 \pm 0.13$ \\
\hline $\mathrm{I}$ & $1.04 \pm 0.30^{\dagger}$ & $0.39 \pm 0.10$ \\
\hline $\mathbf{J}$ & $3.14 \pm 0.62^{\dagger}$ & $0.38 \pm 0.02$ \\
\hline
\end{tabular}

${ }^{*} \mathrm{~A}, \mathrm{H}, \mathrm{I}$, and $\mathrm{J}=$ Control,; i.p. melatonin $(\mathrm{mg} / \mathrm{kg}$ ) before torsion lasting one, three and five hours. ${ }^{t} p<0.05$

Table 4: Malondialdehyde in ipsi-lateral and contra-lateral testis with melatonin administered before de-torsion

\begin{tabular}{|c|c|c|}
\hline \multirow[t]{2}{*}{ Group* } & MDA, Mean (SD) & $\mu \mathrm{mol} / \mathrm{mg}$ \\
\hline & Right testis & Left testis \\
\hline $\bar{A}$ & $0.38 \pm 0.01$ & $0.36 \pm 0.13$ \\
\hline $\mathrm{K}$ & $0.50 \pm 0.14^{+}$ & $0.38 \pm 0.16$ \\
\hline $\mathrm{L}$ & $1.40 \pm 0.04^{+}$ & $0.40 \pm 0.02$ \\
\hline$M$ & $3.20 \pm 0.62^{\dagger}$ & $0.44 \pm 0.10$ \\
\hline
\end{tabular}

* A, $\mathrm{K}, \mathrm{L}$, and $\mathrm{M}=\mathrm{Control},-$ torsion for one, three and five hours respectively, followed by intraperitoneal melatonin $1 \mathrm{mg} / \mathrm{kg}$ before detorsion lasting 90 minutes. ${ }^{\dagger} \mathrm{p}<0.05$.

MDA levels with melatonin administered before de-torsion. There was a significant decrease in MDA levels in the torted testis in groups $\mathrm{K}$ and L (Table 4) but not in group $M$ compared to their corresponding groups in Table 2. There was no significant difference between the MDA levels in the contralateral testis in groups K,L,M (Table 4), compared to their corresponding groups in Table 2.

Histology of the testis following $720^{\circ}$ counterclockwise torsion lasting one, three and five hours.

Transverse section of testes of intact rat showed normal interstitium, seminiferous tubules, and well differentiated seminiferous epithelium.
After 1 hour of $720^{\circ}$ counterclockwise torsion, oedema of the interstitial tissues and disruption of the seminiferous tubule was evident. After 1 hour of $720^{\circ}$ counterclockwise torsion, followed by de-torsion for 90 minutes, there was further disruption of the testicular architecture with evidence of destruction of the seminiferous tubular epithelium. After 3 hours of $720^{\circ}$ counterclockwise torsion, there was severe oedema of the seminiferous tubules. After 3 hours of $720^{\circ}$ counterclockwise torsion, followed by de-torsion for $90 \mathrm{~min}$ utes, oedema was reduced but there was further disruption of the seminiferous tubular structure. After 5 hours of $720^{\circ}$ counterclockwise, there was severe necrosis of the seminiferous tubules.

\section{DISCUSSION}

Melatonin is a free radical scavenger that directly neutralizes a number of free radicals and reactive oxygen and nitrogen species, and stimulates antioxidant enzymes. ${ }^{6,7}$ It has therefore been used as a protective agent against a wide variety of processes and agents that damage tissues via free radical mechanisms.

This study demonstrates the adverse effect of testicular torsion and de-torsion on ipsilateral and contralateral testicular lipid peroxidation, and its amelioration by melatonin administration. These damaging effects have in previous reports been attributed to reduced blood flow, 8,9 increased generation of reactive oxygen species, ${ }^{10,11}$ DNA damage, ${ }^{12}$ germ-cell specific apoptosis ${ }^{13}$ and increased adhesion of neutrophils to testicular subtunical venules. ${ }^{14}$ There has been contradicting reports about the role of lipid peroxidation in torsion-detorson injuries, with some authors supporting a role for free radicals ${ }^{15,16}$ and others denying such a role. ${ }^{17}$ The present study supports a role for free radicals in testicular injury following ischaemia-reperfusion. The lipid peroxidation in the torted testis increased with the duration of ischaemia with a more gradual increase in the contralateral testis. In our model, detorsion caused a greater increase in testicular MDA in the ipsilateral testis, but only when duration of torsion was not more than three hours.
Reperfusion is a beneficial process overall, following relatively brief ischaemia or hypoxia, as much of the damaged tissue can be salvaged by reperfusing with blood and re-introducing oxygen and nutrients. Our data supports the notion that re-perfusion contributes significantly to the testicular injury following ischaemia-reperfusion. This can be attributed to the effect of free radicals, and increased migration of neutrophils to the previously ischaemic tissue. ${ }^{14}$ However in the present study, the role of reperfusion seems to become relatively insignificant after three hours of complete ischaemia. This is probably because the testis becomes infarcted and therefore can no longer be damaged further as it is not possible to further damage a dead tissue. The duration of ischaemia from which the testis is able to recover depends on the extent of the arterial twist. The more the twist, the less the duration from which the testis is able to recover.

For arterial occlusion to occur there must be multiple twisting of the spermatic cord, whereas arteriolar stasis develops secondary to venous occlusion with fewer twists. Experimentally, complete cessation of arterial inflow occurs at 300540 degrees of torsion, and 3-4 complete turns (1080-1440degrees) produces irreversible damage after 2 hours. ${ }^{1}$ Torsion of 90 degrees for periods as long as 7 days fail to cause necrosis in $50 \%$, and 360 degrees causes necrosis in all cases within 24 hours. ${ }^{18}$

In this study, intra-peritoneal melatonin administered before torsion was unable to significantly reduce the lipid peroxidation in the ipsi-lateral testis, but significantly reduced the level in the contra-lateral testis toward the control value. Torsion of the ipsi-lateral testicular artery drastically reduces the melatonin available to the torted testis and therefore denies it of any beneficial effects, but by reducing the lipid peroxidation in the contra-lateral testis, suggests that free radicals play a role in the contra-lateral testicular injury resulting from ipsi-lateral testicular torsion.

However, melatonin significantly reduced the lipid peroxidation resulting from the reperfusion of the ipsi-lateral testis. Reperfusion injury has been attributed to a number of factors, 
particularly polymorphonuclear leucocyte accumulation in the reperfused tissue as evidenced by increased myeloperoxidae activity. ${ }^{14}$ The leucocytes are attracted by various chemoattractants released into the ischaemic tissue and accumulate as a result of ischaemia induced up-regulation of endothelial adhesion molecules. ${ }^{19}$ They soon degranulate releasing various chemical agents including free radicals into the tissue causing further damage. The administration of melatonin in this study was able to reduce the damage due to torsion followed by de-torsion apparently by mopping up free radical released from the invading leucocytes, but interestingly in a previous report, melatonin was also able to reduce leucocyte recruitment into the reperfused tissue.$^{20}$ Melatonin is particularly suitable in this regard because of its ability to penetrate all morpho-physiological barriers including blood-testis barrier, and enters all parts of every cell where it prevents oxidative damage and preserves mitochondrial function..$^{21,22,23}$ This is of critical importance to reproductive function because it has been shown that even the early stages of spermatogenesis are sensitive to a moderate, acute reduction in testicular blood flow. ${ }^{24}$

We conclude that lipid peroxidation plays an important role in ischaemiareperfusion injuries of the testis and that the reperfusion injury is significant and sensitive to melatonin which if administered before reperfusion, can significantly decrease the reperfusion injury.

\section{REFERENCES}

1. Visser AJ, Heyns CF. Torsion of the testis and its appendages; Diagnosis and management. BJU International 2000; 72: 200-203.

2. Huang EJ, Kelly RE, Masuda H, Bjerke
HS, Fonkalsud EW. Deleterious effects of testicular venous occlusions in young rats. Surg Gyneco Obstet 1990; 171: 382-7.

3. Akgur FM, Kilinc K, Tanyel FC, Buyukpanukcu N, Hicsonmez A. Ipsilateral and contra-lateral testicular biochemical acute changes after unilateral testicular torsion and detorsion. Urology 1994; 44: 413-8.

4. Liu J, Yeo HC, Doniger SJ, Ames BN. Assay of aldehydes from lipid peroxidation: gas chromatography-mass spectrometry compared to thiobarbituric acid. Anal Biochem. 1997; 245: 161-166.

5. Buege JA, Aust SD. Microsomal lipid peroxidation in: Fleischer S, Packer L. Eds. Methods in Enzymology LII. 1978; 302 330. New York Academic press.

6. Reiter RJ, Tan DX, Calw JR . Pharmacology and physiology of melatonin in the reduction of oxidative stress in vivo. Biol. Signals Recept. 2000; 9: 160-71.

7. Reiter RJ, Tan DX, Osuna C, Gitto E. Actions of Melatonin in the reduction of oxidative stress: a review. $J$. Biol. Med. Sci. 2000; 7: 444-58.

8. Savas C, Ozogul C, Karaoz E, Bezir M. Ishaemia, whether from ligation or torsion, causes ultra-structural changes on the contra-lateral testis. Scand. $J$ Urol Nephrol. 2002; 36: 302-6.

9. Savas C, Dindar H, Aras T, Yucesan S. Pentoxifylline improves blood flow to both testes in testicular torsion. Int Uro.l Nephrol. 2002; 33: 81-5.

10. Sharma RK, Pasqualotto FF, Nelson DR, Thomas AJ, Agarwal A. The reactive oxygen species total antioxidant capacity score is a new measure of oxidative stress to predict male infertility. Hum. Reprod. 1999; 14: 2801-2807.

11. Ozokutan BH. Muhtaroglu S, Tekin Y .The role of nitric oxide in testicular Ischaemic-reperfusion injury. $J$ Pediatr Surg. 2000; 35: 101-103.

12. Rajesh T, Doreswamy K, Shrilatha B, Muralidhara A. Oxidative stress associated DNA damage in testis of mice: induction of abnormal sperms and effects on fertility. Mutat Res. 2002; 513: 103-111.
13. Turner TT, Tung KS, Tomomasa $\mathrm{H}$, Wilson LW. Acute testicular ischaemia results in germ cell-specific apoptosis in the rat. Biol Reprod. 1997; 57: 1267-74.

14. Thiangurajan RR, Winn RK, Karlan YM. The role of leukocytes and endothelial adhesion molecules in Ischaemiareperfusion injury. Thromb Haemost 1997; 78: 310-314.

15. Halliwell B, Gutteridge J. Free radicals in biology and medicine. Third Edition. Oxford Science Publication; 1999; page 647.

16. Ozturk A, Baltaci AK, Mogulkoc R, Ozturk B. The effect of prophylactic melatonin administration on reperfusion damage in experimental testis ischaemiareperfusion. Neuroendocrine Lett. 2003; 24: $170-2$

17. Prillaman HM, Turner TT. Rescue of testicular function after acute experimental torsion. J Urol 1997; 157: 340-345

18. Sonda LP, Lapides J. Experimental torsion of the spermatic cord. Surg Forum. $1961 ; 12: 502-4$.

19. Granger DN, Kubes P. The microcirculation and inflammation modulation of leukocytes-endothelial cell adhesions. J Leuk Biol 1994; 55: 662.

20. Lysiak JJ, Nguyen QA, Turner YY. Peptide and non-peptide reactive oxygen scavengers provide partial rescue of the testis after torsion. $J$ Androl. 2002; 23: 400-9.

21. Dario AC, Miguel M, Manuel M, Josefa L, Reiter RJ. Melatonin, mitochondria and cellular bio-energetics. J Pineal Res. 2001; 30: 65-77.

22. Tan DX, Manchester LG, Reiter RJ, Claw JR. Significance of melatonin in anti-oxidative defense systems: reactions and products. Biol. signals recept.2000; 9: 137-59.

23. Tan DX, Manchester LC, Reiter RJ. Melatonin directly scavenges hydrogen peroxide: a potentially new metabolic pathway of melatonin bio-transformation. Free Radic Biol. Med. 2000; 29: 1177-85.

24. Anders B, Ola C, Lissbrant E: Effects of acute graded reductions in testicular blood flow on testicular morphology in the adult rat. Biol Reprod 2001; 64: 13-20. 